\title{
CCR7 and CXCR4 expression predicts lymph node status including micrometastasis in gastric cancer
}

\author{
TAKAAKI ARIGAMI, SHOJI NATSUGOE, YOSHIKAZU UENOSONO, SHIGEHIRO YANAGITA, \\ HIDEO ARIMA, MUNETSUGU HIRATA, SUMIYA ISHIGAMI and TAKASHI AIKOU \\ Department of Surgical Oncology and Digestive Surgery, Field of Oncology, \\ Course of Advanced Therapeutics, Kagoshima University Graduate School of \\ Medical and Dental Sciences, 8-35-1 Sakuragaoka, Kagoshima 890-8520, Japan
}

Received March 6, 2009; Accepted May 4, 2009

DOI: 10.3892/ijo_00000308

\begin{abstract}
The chemokine receptors CCR7 and CXCR4 play a major role in the mechanism of lymph node metastasis from primary tumor cells. We postulated that their expression in gastric tumor cells could predict lymph node status including lymph node micrometastasis (LNMM). We assessed CCR7 and CXCR4 expression in 93 resected gastric tumor specimens by immunohistochemistry. Dissected lymph nodes were examined by reverse transcription-polymerase chain reaction and immunohistochemistry using cytokeratin monoclonal antibody to detect LNMM in addition to hematoxylin-eosin (H\&E) staining. Levels of CCR7 and CXCR4 expression were high in $26.9 \%$ (25/93) and in 32.3\% (30/93), respectively of tumor cells and the levels significantly correlated with lymph node metastasis according to $\mathrm{H} \& \mathrm{E}$ staining $(\mathrm{P}=0.0212$ and $\mathrm{P}=0.0115$, respectively). We identified LNMM in 25 of 83 (30.1\%) node-negative patients. Both CCR7 and CXCR4 expression significantly correlated with lymph node status including $\mathrm{LNMM}(\mathrm{P}=0.0092$ and $\mathrm{P}=0.0075$, respectively). Furthermore, levels of combined CCR7 and CXCR4 expression significantly correlated with lymph node metastatic status $(P=0.0021)$. Assessment of CCR7 and CXCR4 expression in gastric cancer is a useful tool for predicting lymph node metastatic status including LNMM.
\end{abstract}

\section{Introduction}

Chemokines are small secreted proteins that presently comprise subfamilies $\mathrm{C}, \mathrm{CC}, \mathrm{CXC}$, and $\mathrm{CX} 3 \mathrm{C}$ based on the arrangement of their cysteine residues in the $\mathrm{NH}_{2}$-terminal (1). These

Correspondence to: Dr Takaaki Arigami, Department of Surgical Oncology and Digestive Surgery, Field of Oncology, Course of Advanced Therapeutics, Kagoshima University Graduate School of Medical and Dental Sciences, 8-35-1 Sakuragaoka, Kagoshima 890-8520, Japan

E-mail: arigami@m.kufm.kagoshima-u.ac.jp

Key words: CCR7, CXCR4, lymph node micrometastasis, gastric cancer chemokines act through their G-protein-linked receptors on target cells (2). Many chemokine receptors have been identified and their activation regulates cytoskeletal rearrangement, adhesion, and directional migration $(3,4)$. Recent studies have demonstrated that chemokines and their receptors principally function as a signaling pathway in leukocyte trafficking and lymphocyte homing $(5,6)$. Furthermore, these signaling pathways play an important role in tumor progression (7). Müller et al (8) reported that at least the chemokine receptors CCR7 and CXCR4 are highly expressed in human breast cancer cell lines and primary breast tumors and that lymph nodes, which are representative secondary metastatic sites of breast cancer, highly express their ligands CCL21 and CXCL12. These results indicate that CCR7 and CXCR4 expressed by breast tumor cells play a major role in the mechanism of lymph node metastasis from primary tumor cells.

Lymph nodes are the most common metastatic sites and nodal metastasis is recognized as an important prognostic factor in gastric cancer (9-11). Therefore, patients with lymph node metastasis have a poor prognosis, despite complete resection (R0). On the other hand, endoscopic mucosal resection (EMR) and endoscopic sub-mucosal dissection (ESD) without lymphadenectomy have been widely applied in Japan to treat mucosal gastric cancer (12-14). However, lymph node metastasis in mucosal and submucosal gastric cancer is pathologically detectable in $2-4$ and $13-20 \%$, respectively (15-19).

We previously reported that lymph node micrometastasis (LNMM) can be identified by immunohistochemistry (IHC) and by reverse transcription-polymerase chain reaction (RT-PCR) assays in patients with gastric cancer who are pathologically node-negative ( $\mathrm{pN} 0$ ) according to conventional hematoxylin-eosin $(H \& E)$ staining $(20,21)$. The clinical significance of LNMM in gastric cancer is controversial (22). However, $92 \%$ of gastric tumor cells within LNMM are Ki-67 positive (23), indicating the potential proliferative activity of LNMM in gastric cancer. Accordingly, part of the strategic surgical approach to treating gastric cancer is to detect lymph node metastasis including LNMM. However, to preoperatively assess LNMM using methods such as computed tomography and ultrasound is difficult. To date, no reports have revealed the relationship between LNMM and CCR7 and CXCR4 expression in gastric cancer. Additionally, no better biomarkers 
for predicting lymph node status including LNMM have been identified in gastric cancer.

The present study investigates CCR7 and CXCR4 expression in gastric tumors and examines the relationship between such expression and lymph node status including LNMM.

\section{Materials and methods}

Gastric cancer cell lines. We constructed standard curves for RT-PCR assays using the gastric cancer cell line, MKN-45, which was cultured in RPMI-1640 (Nissui Pharmaceutical Co., Ltd., Tokyo, Japan) supplemented with $10 \%$ fetal calf serum (Mitsubishi Kasei, Tokyo, Japan) and $100 \mathrm{U} / \mathrm{ml}$ each of penicillin and streptomycin at $37^{\circ} \mathrm{C}$ in a humidified $5 \%$ $\mathrm{CO}_{2}$ atmosphere as described $(20,21)$.

Patients. We enrolled 93 patients (65 men and 28 women; age range, 41-84 years; average 64 years) with gastric cancer who underwent curative gastrectomy with lymphadenectomy at Kagoshima University Hospital between 2003 and 2005. Patients who had undergone preoperative radiation therapy or chemotherapy were excluded from the study. Tumors were classified and staged based on the Japanese classification of gastric carcinoma (24). Fourteen, 51 and 28 tumors were located in the upper, middle and lower thirds of the stomach, respectively. Eighty-one and 12 patients had T1 (invasion of mucosa or submucosa) and T2 (invasion of muscularis propria or subserosa)/T3 (penetration of serosa) tumors, respectively, that were histopathologically classified as differentiated $(n=55$; papillary, well and moderately differentiated tubular adenocarcinomas) and undifferentiated $(n=38$; poorly differentiated adenocarcinoma, mucinous adenocarcinoma, and signet-ring cell carcinoma). Paraffin-embedded archival tissue (PEAT) specimens obtained from these resected primary tumors were histopathologically confirmed by a surgical pathologist. All specimens were collected from the patients after informed consent had been obtained in accordance with the institutional guidelines of our hospital.

Lymph nodes. We examined 2,415 lymph nodes from 93 patients with gastric cancer (range 2-69 nodes; average 26 nodes). The negative controls for LNMM for our RT-PCR assays comprised 30 normal lymph nodes from 14 patients without cancer (gall bladder stone, $n=6$; gastric adenoma, $\mathrm{n}=4$; gastric ulcer, $\mathrm{n}=3$; Crohn's disease, $\mathrm{n}=1$ ). The lymph nodes were cut into 2 blocks at the plane of the largest dimension. One block was suspended in $1 \mathrm{ml}$ of Isogen (Nippon Gene, Toyama, Japan) and immediately stored at $-80^{\circ} \mathrm{C}$. The other block was fixed in $10 \%$ formaldehyde, embedded in paraffin, and then cut into $3 \mu \mathrm{m}$ sections for $\mathrm{H} \& \mathrm{E}$ staining and IHC using a monoclonal antibody (mAb) to cytokeratin $(\mathrm{CK})$.

RNA extraction. Thawed lymph nodes were homogenized in FastPrep (Qbiogene, Inc., Carlsbad, CA, USA) and then total RNA was extracted, isolated and purified using phenolchloroform as described $(20,21)$. The concentration and purity of the total RNA were determined using a GeneQuant pro UV/Vis spectrophotometer (Amersham Pharmacia Biotech, Cambridge, UK).
Primers and probes. Primer and probe sequences of carcinoembryonic antigen (CEA) and glyceraldehyde-3-phosphatase dehydrogenase (GAPDH) were designed for RT-PCR assays as described $(20,21)$. The forward primers, donor and acceptor probe sequences, and reverse primers for CEA and GAPDH were as follows: CEA (forward), 5'-TGTCGGCATCATGAT TGG-3'; (donor and acceptor), 5'-CCTGAAATGAAGAA ACTACACCAGGGC-3'-fluorescein and 5'-LC-Red640GCTATATCAGAGCAACCCCAACCAGC-3'-phosphorylation; (reverse), 5'-GCAAATGCTTTAAGGAAGAAGC-3'; GAPDH (forward), 5'-TGAACGGGAAGCTCACTGG-3'; (donor and acceptor), 5'-TCAACAGCGACACCCACTCCT3'-fluorescein and 5'-LC-Red640-CACCTTTGACGCTGGG GCT-3'-phosphorylation; (reverse), 5'-TCCACCACCCTGT TGCTGTA-3'. The integrity of the RNA was confirmed by RT-PCR assays using GAPDH.

$R T-P C R$ assay. Contamination with genomic DNA was avoided using DNase-I (Invitrogen, Life Technologies, Foster City, CA, USA) and complementary DNA (cDNA) was synthesized using the Advantage RT-for-PCR kit (Clontech Laboratories, Inc., Palo Alto, CA, USA) as described (20,21). All RT-PCR assays were performed using the LightCycler system (Roche Diagnostics, Mannheim, Germany). The reaction mixtures contained cDNA, primers, fluorescent and LC-Red probes, $\mathrm{MgCl}_{2}$, LightCycler FastStart DNA Master hybridization probes (Roche) and anti-Taq DNA polymerase antibody (TaqStart antibody, Clontech Laboratories). The amplification profile consisted of $95^{\circ} \mathrm{C}$ for $10 \mathrm{~min}$ followed by 35 cycles of denaturation at $95^{\circ} \mathrm{C}$ for $10 \mathrm{sec}$, annealing at $60^{\circ} \mathrm{C}$ for $15 \mathrm{sec}$, and extension at $72^{\circ} \mathrm{C}$ for $5 \mathrm{sec}$. All primers and probes were synthesized and purified by reverse-phase high-performance liquid chromatography and the optimal reagent concentrations and PCR cycling conditions were established at the Nihon Gene Research Laboratories (Sendai, Japan). Standard curves for each assay were generated using a threshold cycle of serially diluted MKN-45 cells as described $(20,21)$. Quantitative data were analyzed using LightCycler software (Roche). All RT-PCR assays included positive (gastric cancer cell line), negative (normal lymph nodes from patients without cancer) and reagent controls (reagents without cDNA). Our RT-PCR assay system was optimized and established for detecting LNMM as described $(20,21)$.

Immunohistochemical staining. We assessed LNMM in all dissected lymph nodes by IHC staining using a CK AE1/AE3 mAb (Dako Corp., Carpinteria, CA, USA) as described $(20,23)$. The PEAT sections were deparaffinized in xylene and rehydrated in ethanol, and then endogenous peroxidase activity was blocked by 5-min incubation in methanol containing $3 \%$ hydrogen peroxide. The sections were then immersed in proteinase $\mathrm{K}$ (Dako Corp.) to activate the antigen and incubated with CK mAb diluted 1:200 for $30 \mathrm{~min}$. The sections were washed with phosphate-buffered saline (PBS) and $\mathrm{CK}$ was stained using the ABC method (Vectastain ABC kit, Vector Laboratories, Inc., Burlingame, CA, USA) (25) and visualized using diaminobenzidine tetrahydrochloride (DAB). The negative control sections were processed identically but without the primary antibody. The positive controls were PEAT 

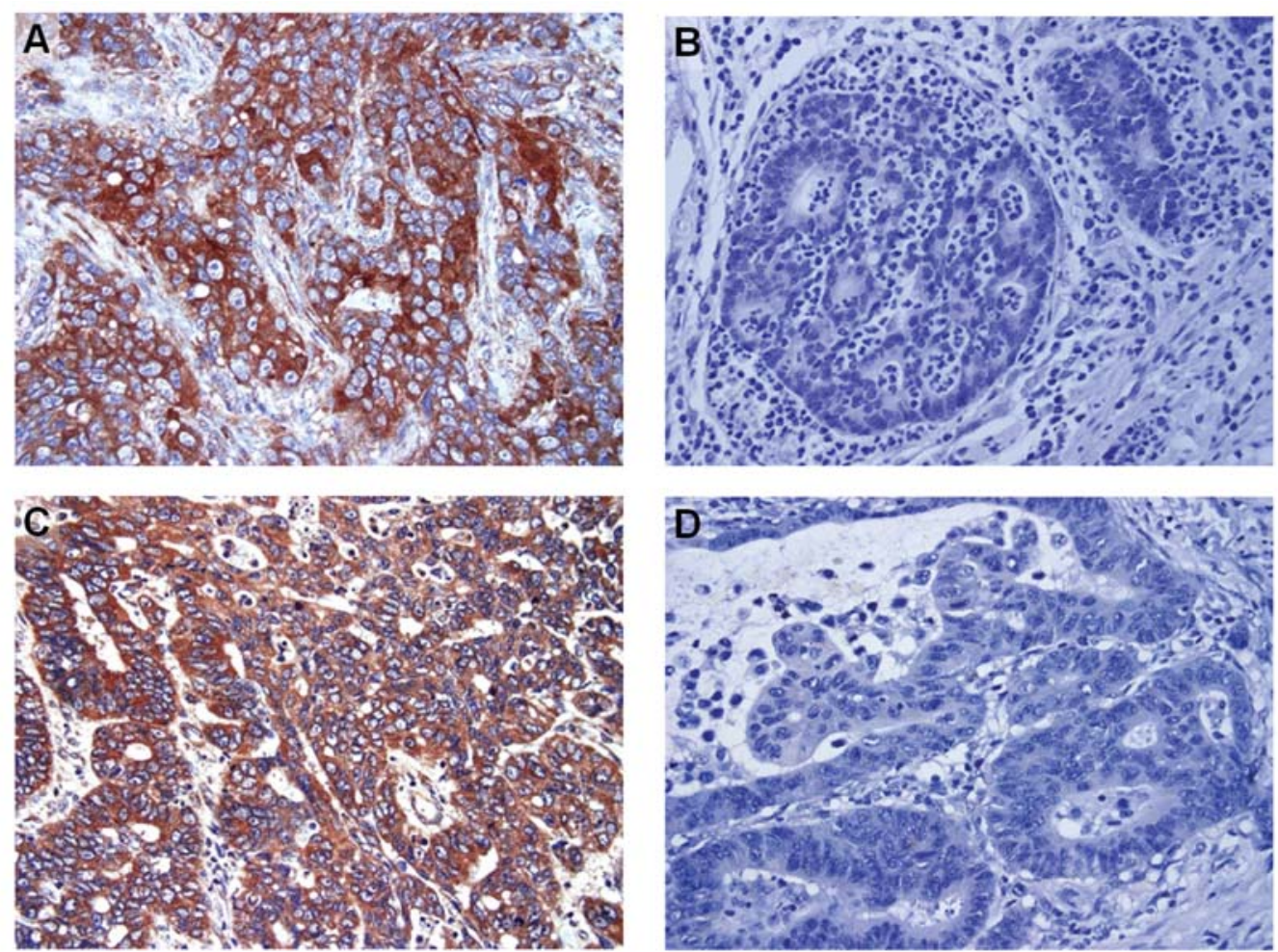

Figure 1. Representative IHC of CCR7 and CXCR4 expression in gastric cancer tissues. Tumor cells with: (A), high; and (B), low expression of CCR7; and (C), high; and (D), low expression of CXCR4. Original magnification x400.

sections of normal gastric mucosa that were consistently positive for CK.

The PEAT sections (3- $\mu \mathrm{m}$ thick) with resected primary tumors were incubated on slides at $50^{\circ} \mathrm{C}$ overnight, deparaffinized with xylene, and then rehydrated with a graded series of ethanol. The sections were immersed in methanol containing $0.3 \%$ hydrogen peroxide for 30 min to block endogenous peroxidase, washed three times for 5 min each with PBS, and then non-specific binding was blocked with $1 \%$ bovine serum albumin in PBS at room temperature for $30 \mathrm{~min}$. The sections were incubated at $4^{\circ} \mathrm{C}$ overnight with anti-CCR7 (BD Biosciences, San Jose, CA, USA) and CXCR4 mAbs (R\&D Systems, Minneapolis, MN, USA) diluted 1:100 in PBS. After three 5-min washes in PBS, the reactions for CCR7 and CXCR4 were developed using the ABC method (Vectastain ABC kit, Vector Laboratories) (25) and visualized using DAB. Negative controls were treated with PBS without primary antibodies under the same conditions.

Two independent investigators (T. Arigami and S. Natsugoe) blinded to the clinicopathological data of the patients evaluated the IHC staining for CCR7 and CXCR4. High expression was defined as the presence of CCR7 and CXCR4 immunoreactivity in over $30 \%$ of the cancer cells $(26,27)$. Expression of CCR7 and CXCR4 was evaluated in 10 fields each containing 100 cells using light microscopy (magnification x200).

Statistical analysis. Data were statistically compared using the $\chi^{2}$ and Fisher's exact tests. All statistical calculations were performed using SAS statistical software (SAS Institute Inc. Cary, NC). A $\mathrm{P}<0.05$ was considered statistically significant.

\section{Results}

CCR7 and CXCR4 expression in gastric tumors. Both CCR7 and CXCR4 were expressed in the cell membrane and/or cytoplasm of gastric tumors. CCR7 and CXCR4 were highly expressed in $25(26.9 \%)$ and in $30(32.3 \%)$ of 93 patients with gastric cancer, respectively (Fig. 1).

Correlation between CCR7 and CXCR4 expression and clinicopathological factors. CCR7 expression significantly correlated with depth of tumor, lymphatic and venous invasion, and lymph node metastasis $(\mathrm{P}=0.0024,0.0004,<0.0001$ and 0.0212 , respectively), and the CXCR4 expression significantly correlated with histological type, tumor size, lymphatic and venous invasion, and lymph node metastasis $(\mathrm{P}=0.0238$, $0.0162,0.0009,0.0005$ and 0.0115 , respectively; Table I).

Correlation between CCR7 and CXCR4 expression and lymph node status including LNMM. We used immunohistochemical staining with CK mAb and RT-PCR to assess LNMM in lymph nodes diagnosed as pN0 by H\&E staining. We detected LNMM in 25 of 83 patients $(30.1 \%)$ with such pN0 gastric cancers.

To assess the relationship between CCR7 and CXCR4 expression and lymph node status including LNMM, we classified the patients according to LNMM status as nodenegative/LNMM-negative, node-negative/LNMM-positive and node-positive (Table II). Lymph node metastatic status including LNMM was significantly higher among patients with high levels, than with low levels of CCR7 and CXCR4 expression ( $\mathrm{P}=0.0092$ and 0.0075 , respectively). 
Table I. Relationship between CCR7/CXCR4 expressions and clinicopathological factors in 93 patients with gastric cancer.

\begin{tabular}{|c|c|c|c|c|c|c|}
\hline \multirow[b]{2}{*}{ Clinicopathological factors } & \multicolumn{3}{|c|}{ CCR7 expression } & \multicolumn{3}{|c|}{ CXCR4 expression } \\
\hline & $\begin{array}{c}\text { Low } \\
\mathrm{n}=68(\%)\end{array}$ & $\begin{array}{c}\text { High } \\
\mathrm{n}=25(\%)\end{array}$ & P-value & $\begin{array}{c}\text { Low } \\
\mathrm{n}=63(\%)\end{array}$ & $\begin{array}{c}\text { High } \\
\mathrm{n}=30(\%)\end{array}$ & P-value \\
\hline \multicolumn{7}{|l|}{ Gender } \\
\hline Male & $48(73.8)$ & $17(26.2)$ & \multirow[t]{2}{*}{0.8039} & $44(67.7)$ & $21(32.3)$ & \multirow[t]{2}{*}{$>0.9999$} \\
\hline Female & $20(71.4)$ & $8(28.6)$ & & $19(67.9)$ & $9(32.1)$ & \\
\hline \multicolumn{7}{|l|}{ Tumor location } \\
\hline Upper & $9(64.3)$ & $5(35.7)$ & \multirow[t]{3}{*}{0.6415} & $9(64.3)$ & $5(35.7)$ & \multirow[t]{3}{*}{0.2746} \\
\hline Middle & $39(76.5)$ & $12(23.5)$ & & $38(74.5)$ & $13(25.5)$ & \\
\hline Lower & $20(71.4)$ & $8(28.6)$ & & $16(57.1)$ & $12(42.9)$ & \\
\hline \multicolumn{7}{|l|}{ Histological type } \\
\hline Differentiated & $36(65.5)$ & $19(34.5)$ & \multirow[t]{2}{*}{0.0578} & $32(58.2)$ & $23(41.8)$ & \multirow[t]{2}{*}{0.0238} \\
\hline Undifferentiated & $32(84.2)$ & $6(15.8)$ & & $31(81.6)$ & $7(18.4)$ & \\
\hline \multicolumn{7}{|l|}{ Depth of tumor invasion } \\
\hline pT1 & $64(79.0)$ & $17(21.0)$ & \multirow[t]{2}{*}{0.0024} & $58(71.6)$ & $23(28.4)$ & \multirow[t]{2}{*}{0.0506} \\
\hline pT2-pT3 & $4(33.3)$ & $8(66.7)$ & & $5(41.7)$ & $7(58.3)$ & \\
\hline \multicolumn{7}{|l|}{ Tumor size } \\
\hline$<30 \mathrm{~mm}$ & $34(75.6)$ & $11(24.4)$ & \multirow[t]{2}{*}{0.6463} & $36(80.0)$ & $9(20.0)$ & \multirow[t]{2}{*}{0.0162} \\
\hline$\geq 30 \mathrm{~mm}$ & $34(70.8)$ & $14(29.2)$ & & $27(56.2)$ & $21(43.8)$ & \\
\hline \multicolumn{7}{|l|}{ Lymphatic invasion } \\
\hline Negative & $60(82.2)$ & $13(17.8)$ & \multirow[t]{2}{*}{0.0004} & $56(76.7)$ & $17(23.3)$ & \multirow[t]{2}{*}{0.0009} \\
\hline Positive & $8(40.0)$ & $12(60.0)$ & & $7(35.0)$ & $13(65.0)$ & \\
\hline \multicolumn{7}{|l|}{ Venous invasion } \\
\hline Negative & $64(82.1)$ & $14(17.9)$ & \multirow[t]{2}{*}{$<0.0001$} & $59(75.6)$ & $19(24.4)$ & \multirow[t]{2}{*}{0.0005} \\
\hline Positive & $4(26.7)$ & $11(73.3)$ & & $4(26.7)$ & $11(73.3)$ & \\
\hline \multicolumn{7}{|l|}{ Lymph node metastasis ${ }^{a}$} \\
\hline Negative & $64(77.1)$ & $19(22.9)$ & \multirow[t]{2}{*}{0.0212} & $60(72.3)$ & $23(27.7)$ & \multirow[t]{2}{*}{0.0115} \\
\hline Positive & $4(40.0)$ & $6(60.0)$ & & $3(30.0)$ & $7(70.0)$ & \\
\hline
\end{tabular}

pT1, invasion of mucosa or submucosa; pT2, invasion of muscularis propria or subserosa; pT3, penetration of serosa. ${ }^{a}$ Lymph node metastasis was identified based on hematoxylin-eosin staining.

Table II. Relationship between CCR7/CXCR4 expressions and lymph node status.

\begin{tabular}{|c|c|c|c|c|}
\hline & $\begin{array}{c}\mathrm{pN}(-) / \mathrm{LNMM}(-) \\
\mathrm{n}=58\end{array}$ & $\begin{array}{c}\mathrm{pN}(-) / \mathrm{LNMM}(+) \\
\mathrm{n}=25\end{array}$ & $\begin{array}{l}\mathrm{pN}(+) \\
\mathrm{n}=10\end{array}$ & P-value \\
\hline \multicolumn{5}{|c|}{ CCR7 expression } \\
\hline Low $(n=68)$ & $48(82.8)$ & $16(64.0)$ & $4(40.0)$ & 0.0092 \\
\hline High $(n=25)$ & $10(17.2)$ & $9(36.0)$ & $6(60.0)$ & \\
\hline \multicolumn{5}{|c|}{ CXCR4 expression } \\
\hline Low $(n=63)$ & 45 (77.6) & $15(60.0)$ & $3(30.0)$ & 0.0075 \\
\hline High $(n=30)$ & $13(22.4)$ & $10(40.0)$ & $7(70.0)$ & \\
\hline
\end{tabular}

LNMM, lymph node micrometastasis.

Table III. Relationship between CCR7 and CXCR4 expression.

\begin{tabular}{lccc}
\hline & \multicolumn{2}{c}{ CXCR4 expression (\%) } & \\
\cline { 2 - 3 } CCR7 expression & Low $(\mathrm{n}=63)$ & High $(\mathrm{n}=30)$ & P-value \\
\hline Low $(\mathrm{n}=68)$ & $55(59.1)$ & $13(14.0)$ & $<0.0001$ \\
High $(\mathrm{n}=25)$ & $8(8.6)$ & $17(18.3)$ & \\
\hline
\end{tabular}

Relevance of CCR7 and CXCR4 expression in predicting lymph node status. Expression of CCR7 and CXCR4 were significantly correlated $(\mathrm{P}<0.0001$; Table III). Based on the status of CCR7 and CXCR4, all patients were assigned to groups with low, intermediate or high expression (low expression of both CCR7 and CXCR4, low expression of either CCR7 or CXCR4 and high expression of both CCR7 
Table IV. Relationship between lymph node status and expression patterns of CCR7 and CXCR4.

\begin{tabular}{lccc}
\hline $\begin{array}{l}\text { Expression patterns of } \\
\text { CCR7 and CXCR4 }\end{array}$ & $\begin{array}{c}\mathrm{pN}(-) / \mathrm{LNMM}(-) \\
\mathrm{n}=58\end{array}$ & $\begin{array}{c}\mathrm{pN}(-) / \mathrm{LNMM}(+) \\
\mathrm{n}=25\end{array}$ & $\begin{array}{c}\mathrm{pN}(+) \\
\mathrm{n}=10\end{array}$ \\
\hline Low $(\mathrm{n}=55)$ & $40(69.0)$ & $12(48.0)$ & $3(30.0)$ \\
Intermediate $(\mathrm{n}=21)$ & $13(22.4)$ & $7(28.0)$ & $1(10.0)$ \\
High $(\mathrm{n}=17)$ & $5(8.6)$ & $6(24.0)$ & $6(60.0)$
\end{tabular}

LNMM, lymph node micrometastasis.

and CXCR4, respectively; Table IV). We found that lymph node metastatic status including LNMM was significantly higher among patients in the group with high levels, than with low levels of CCR7 and CXCR4 expression $(\mathrm{P}=0.0021)$.

\section{Discussion}

The chemokine receptors CCR7 and CXCR4 are expressed in tumor cells of breast cancer and malignant melanoma, as well as pancreatic, colorectal and esophageal and gastric cancers $(8,28-33)$. The CCL21 and CXCL12 ligands for CCR7 and CXCR4 are abundant in lymph nodes (8). Wiley et al (34) reported that CCR7 expression enhances the metastasis of murine melanoma cells to draining lymph nodes in mice. Furthermore, Müller et al (8) reported that injection of an anti-CXCR4 antibody significantly reduced the metastasis of breast cancer cells to regional lymph nodes in immunodeficient mice. Thus, the CCR7 and CXCR4 signaling pathway might play crucial roles in the mechanism of lymph node metastasis from primary tumor cells. Therefore, we examined the correlation between CCR7 and CXCR4 expression and lymph node status.

We initially investigated CCR7 and CXCR4 expression in PEAT sections of primary gastric tumors and the relationships with clinicopathological factors. We found that CCR7 and CXCR4 expression in gastric tumor cells visualized and identified by IHC correlated with depth of tumor invasion, lymphatic invasion, venous invasion and lymph node metastasis determined by $\mathrm{H} \& \mathrm{E}$ staining. These findings indicated a close relationship between tumor progression and expression of both CCR7 and CXCR4.

We previously demonstrated the importance of LNMM when selecting therapeutic strategies for patients with gastric cancer $(20,21,35)$. Therefore, lymph node metastatic status, including LNMM should be predicted. We postulated that CCR7 and CXCR4 expression correlated with lymph node metastatic status including LNMM in gastric cancer. Our findings showed that CCR7 and CXCR4 expression significantly correlated with lymph node status including LNMM. We then examined whether CCR7 and CXCR4 expression could predict lymph node status. We demonstrated that lymph node status, including LNMM, was more closely correlated with expression of both CCR7 and CXCR4 than with either alone. Assessment of CCR7 and CXCR4 expression in preoperative biopsy specimens might thus yield valuable information for predicting preoperative lymph node status including LNMM.
An antagonist of CXCR4 can suppress tumor migration, invasion, and lung metastasis in an animal model (36-40). Several CXCR4 antagonists, such as AMD3100, 4F-benzoylTE14011 and TN14003, are currently available (36-40). We showed here that expression of CCR7 and CXCR4 in gastric tumors significantly correlated with lymph node metastatic status, lymphatic and venous invasion. Therefore, CCR7 and CXCR4 antagonists might represent novel therapeutic agents that could regulate distant metastases, including those to lymph nodes in patients with advanced gastric cancer.

In conclusion, we demonstrated that CCR7 and CXCR4 are both expressed in gastric tumor cells and that their expression correlates with tumor progression and lymph node metastatic status including LNMM. Therefore, CCR7 and CXCR4 are potential markers for predicting lymph node metastatic status in patients with gastric cancer. The evaluation of CCR7 and CXCR4 expression might also serve as a useful means of predicting the presence or absence of LNMM in patients with early gastric cancer who will undergo less invasive surgery such as EMR and ESD. Furthermore, future studies on biological behavior of the gastric tumor cells expressing CCR7 and CXCR4 may allow the development of new immunotherapy inhibiting these signaling pathways for patients with gastric cancer.

\section{Acknowledgements}

This study was supported in part by grants-in-aid for scientific research from the Ministry of Education, Science, Sports, and Culture, Japan.

\section{References}

1. Zlotnik A and Yoshie O: Chemokines: a new classification system and their role in immunity. Immunity 12: 121-127, 2000.

2. Murphy PM: Chemokine receptors: structure, function and role in microbial pathogenesis. Cytokine Growth Factor Rev 7: 47-64, 1996.

3. Butcher EC, Williams M, Youngman K, Rott L and Briskin M: Lymphocyte trafficking and regional immunity. Adv Immunol 72: 209-253, 1999.

4. Campbell JJ and Butcher EC: Chemokines in tissue-specific and microenvironment-specific lymphocyte homing. Curr Opin Immunol 12: 336-341, 2000.

5. Dieu MC, Vanbervliet B, Vicari A, et al: Selective recruitment of immature and mature dendritic cells by distinct chemokines expressed in different anatomic sites. J Exp Med 188: 373-386, 1998.

6. Hirao M, Onai N, Hiroishi $\mathrm{K}$, et al: $\mathrm{CC}$ chemokine receptor-7 on dendritic cells is induced after interaction with apoptotic tumor cells: critical role in migration from the tumor site to draining lymph nodes. Cancer Res 60: 2209-2217, 2000. 
7. Scotton CJ, Wilson JL, Milliken D, Stamp G and Balkwill FR: Epithelial cancer cell migration: a role for chemokine receptors? Cancer Res 61: 4961-4965, 2001.

8. Müller A, Homey B, Soto H, et al: Involvement of chemokine receptors in breast cancer metastasis. Nature 410: 50-56, 2001.

9. Kwon SJ and Kim GS: Prognostic significance of lymph node metastasis in advanced carcinoma of the stomach. Br J Surg 83: 1600-1603, 1996.

10. Takagane A, Terashima M, Abe K, et al: Evaluation of the ratio of lymph node metastasis as a prognostic factor in patients with gastric cancer. Gastric Cancer 2: 122-128, 1999.

11. Nitti D, Marchet A, Olivieri M, Ambrosi A, Mencarelli R, Belluco C and Lise M: Ratio between metastatic and examined lymph nodes is an independent prognostic factor after D2 resection for gastric cancer: analysis of a large European monoinstitutional experience. Ann Surg Oncol 10: 1077-1085, 2003

12. Oda I, Saito D, Tada M, et al: A multicenter retrospective study of endoscopic resection for early gastric cancer. Gastric Cancer 9: 262-270, 2006.

13. Gotoda T: Endoscopic resection of early gastric cancer. Gastric Cancer 10: 1-11, 2007

14. Ogura K, Okamoto M, Sugimoto T, et al: Efficacy and safety of endoscopic submucosal dissection for gastric cancer in patients with liver cirrhosis. Endoscopy 40: 443-445, 2008.

15. Yamao T, Shirao K, Ono H, et al: Risk factors for lymph node metastasis from intramucosal gastric carcinoma. Cancer 77: 602-606, 1996

16. Tsujitani S, Oka S, Saito H, Kondo A, Ikeguchi M, Maeta M and Kaibara N: Less invasive surgery for early gastric cancer based on the low probability of lymph node metastasis. Surgery 125: $148-154,1999$.

17. Cai J, Ikeguchi M, Maeta M and Kaibara N: Micrometastasis in lymph nodes and microinvasion of the muscularis propria in primary lesions of submucosal gastric cancer. Surgery 127: 32-39, 2000.

18. Folli S, Morgagni P, Roviello F, et al: Italian Research Group for Gastric Cancer (IRGGC) (2001). Risk factors for lymph node metastases and their prognostic significance in early gastric cancer (EGC) for the Italian Research Group for Gastric Cancer (IRGGC). Jpn J Clin Oncol 31: 495-499, 2001.

19. Kim DY, Joo JK, Ryu SY, Kim YJ and Kim SK: Factors related to lymph node metastasis and surgical strategy used to treat early gastric carcinoma. World J Gastroenterol 10: 737-740, 2004 .

20. Arigami T, Natsugoe S, Uenosono Y, et al: Lymphatic invasion using D2-40 monoclonal antibody and its relationship to lymph node micrometastasis in $\mathrm{pN} 0$ gastric cancer. Br J Cancer 93: 688-693, 2005

21. Arigami T, Natsugoe S, Uenosono Y, et al: Evaluation of sentinel node concept in gastric cancer based on lymph node micrometastasis determined by reverse transcription-polymerase chain reaction. Ann Surg 243: 341-347, 2006.

22. Ishida K, Katsuyama T, Sugiyama A and Kawasaki S: Immunohistochemical evaluation of lymph node micrometastases from gastric carcinomas. Cancer 79: 1069-1076, 1997.

23. Yanagita S, Natsugoe S, Uenosono Y, et al: Sentinel node micrometastases have high proliferative potential in gastric cancer. J Surg Res 145: 238-243, 2008.

24. Japanese Gastric Cancer Association: Japanese Classification of Gastric Carcinoma. 2nd English Edition. Gastric Cancer 1: 10-24, 1998
25. Hsu SM, Raine L and Fanger H: Use of avidin-biotin-peroxidase complex $(\mathrm{ABC})$ in immunoperoxidase techniques: a comparison between $\mathrm{ABC}$ and unlabeled antibody (PAP) procedures. J Histochem Cytochem 29: 577-580, 1981

26. Tsuzuki H, Takahashi N, Kojima A, Narita N, Sunaga H, Takabayashi T and Fujieda S: Oral and oropharyngeal squamous cell carcinomas expressing CCR7 have poor prognoses. Auris Nasus Larynx 33: 37-42, 2006.

27. Shang ZJ, Liu K and Shao Z: Expression of chemokine receptor CCR7 is associated with cervical lymph node metastasis of oral squamous cell carcinoma. Oral Oncol (In press).

28. Koshiba T, Hosotani R, Miyamoto Y, et al: Expression of stromal cell-derived factor 1 and CXCR4 ligand receptor system in pancreatic cancer: a possible role for tumor progression. Clin Cancer Res 6: 3530-3535, 2000.

29. Mashino K, Sadanaga N, Yamaguchi H, et al: Expression of chemokine receptor CCR7 is associated with lymph node metastasis of gastric carcinoma. Cancer Res 62: 2937-2941, 2002.

30. Ding Y, Shimada Y, Maeda M, et al: Association of CC chemokine receptor 7 with lymph node metastasis of esophageal squamous cell carcinoma. Clin Cancer Res 9: 3406-3412, 2003.

31. Takeuchi H, Fujimoto A, Tanaka M, Yamano T, Hsueh E and Hoon DS: CCL21 chemokine regulates chemokine receptor CCR7 bearing malignant melanoma cells. Clin Cancer Res 10: 2351-2358, 2004

32. Cabioglu N, Yazici MS, Arun B, Broglio KR, Hortobagyi GN, Price JE and Sahin A: CCR7 and CXCR4 as novel biomarkers predicting axillary lymph node metastasis in $\mathrm{T} 1$ breast cancer. Clin Cancer Res 11: 5686-5693, 2005.

33. Schimanski CC, Schwald S, Simiantonaki N, et al: Effect of chemokine receptors CXCR4 and CCR7 on the metastatic behavior of human colorectal cancer. Clin Cancer Res 11: 1743-1750, 2005

34. Wiley HE, Gonzalez EB, Maki W, Wu MT and Hwang ST: Expression of CC chemokine receptor-7 and regional lymph node metastasis of B16 murine melanoma. J Natl Cancer Inst 93: 1638-1643, 2001.

35. Nakajo A, Natsugoe S, Ishigami S, et al: Detection and prediction of micrometastasis in the lymph nodes of patients with $\mathrm{pN} 0$ gastric cancer. Ann Surg Oncol 8: 158-162, 2001.

36. Hatse S, Princen K, Bridger G, De Clercq E and Schols D: Chemokine receptor inhibition by AMD3100 is strictly confined to CXCR4. FEBS Lett 527: 255-262, 2002

37. Liang Z, Wu T, Lou H, et al: Inhibition of breast cancer metastasis by selective synthetic polypeptide against CXCR4. Cancer Res 64: 4302-4308, 2004

38. Mori T, Doi R, Koizumi M, et al: CXCR4 antagonist inhibits stromal cell-derived factor 1-induced migration and invasion of human pancreatic cancer. Mol Cancer Ther 3: 29-37, 2004.

39. Takenaga M, Tamamura $\mathrm{H}$, Hiramatsu $\mathrm{K}$, et al: A single treatment with microcapsules containing a CXCR4 antagonist suppresses pulmonary metastasis of murine melanoma. Biochem Biophys Res Commun 320: 226-232, 2004.

40. Tamamura H, Fujisawa M, Hiramatsu K, et al: Identification of a CXCR4 antagonist, a T140 analog, as an anti-rheumatoid arthritis agent. FEBS Lett 569: 99-104, 2004. 